\title{
Resumption of sex after a second birth: An Australian prospective cohort
}

Ellie A. MCDONALD, PhD ${ }^{1}$, Deirdre GARTLAND, PhD ${ }^{1}$, Hannah WOOLHOUSE, $\mathrm{PhD}^{1}$,Stephanie

J. BROWN, $\mathrm{PhD}^{1,2}$

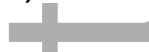

Funding Australian National Health and Medical Research Council (NHMRC) (Grant nos.

199222, 433006 and 491205)

\section{Corresponding author:}

\section{Ellie McDonald}

Healthy Mothers Healthy Families Research Group

Murdoch Children's Research Institute

The Royal Children's Hospital

Flemington Road, Parkville

Victoria, Australia 3052

Email: ellie.mcdonald@mcri.edu.au

Telephone: 61399366583

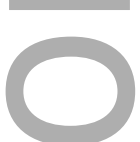

\section{Word count: 3829}

Taking longer to resume sex after the second baby is normal.

Resumption of sex after a second birth

1 Healthy Mothers Healthy Families Research Group, Murdoch Children's Research Institute, Flemington Road, Parkville, 3052, Australia

2 Departments of Paediatrics and General Practice, The University of Melbourne, Parkville, 3052, Australia

This is the author manuscript accepted for publication and has undergone full peer review but has not been through the copyediting, typesetting, pagination and proofreading process, which may lead to differences between this version and the Version of Record. Please cite this article as doi: $10.1111 /$ birt.12363

This article is protected by copyright. All rights reserved 


\section{Acknowledgements}

We are grateful to members of the Maternal Health Study research team who contributed to recruitment and follow-up of the cohort, in particular Ann Krastev and Susan Perlen. We are also extremely grateful to all of the women taking part in the study.

EM planned and conducted analyses and co-wrote the paper. SB wrote the study protocol, took primary responsibility for the design and conduct of the study, contributed to the analysis plan and interpretation of the data, and contributed to writing the paper. EM and DG were responsible for data management.

DG and HW contributed to interpretation of data and contributed to drafts of the paper. All authors have approved the final draft of the manuscript for publication.

This research was supported by project grants from the Australian National Health and Medical Research Council (NHMRC) (Grant nos. 199222, 433006 and 491205); a Vic-Health Public Health Research Fellowship (2002-2006) (SB), an ARC Future Fellowship (SB), an National Health and Medical Research Council Career Development Fellowship (No. 491205, 2008-2011) (SB), and Senior Research Fellowship (No.1103976 , 2016-2020) (SB); a La Trobe University Postgraduate Scholarship (EM); a grant from the Medical Research and Technology in Victoria Fund (ANZ Trustees) and the Victorian Government's Operational Infrastructure Support Programme.

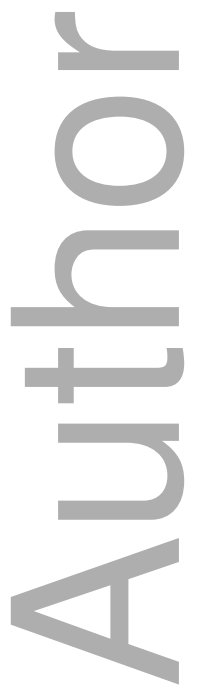


PROF. STEPHANIE JANNE BROWN (Orcid ID : 0000-0001-9812-0067)

4

5

6

7

8

9

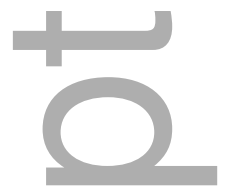

Article type : Original Article

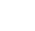
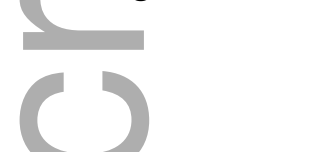

\section{Abstract}

Background Few longitudinal studies have examined women's experiences of sex after childbirth. Much of the advice given to couples about what to expect in relation to sex after childbirth is based on cross-sectional studies.

Objective To investigate timing of resumption of sex after a second birth and assess associations with obstetric factors (method of birth and perineal trauma) and time interval between first and second births.

Method Prospective cohort of 1507 nulliparous women recruited before 25 weeks' gestation in Melbourne, Australia followed-up at 3, 6, 9 and 12 months after first births, and 6 and 12 months after second births. Measures include: obstetric factors and resumption of vaginal sex after first and second births.

Results By eight weeks after their second birth, $56 \%$ of women had resumed vaginal sex, compared with $65 \%$ after their first birth. Women were more likely to resume sex later than eight weeks postpartum if they had a spontaneous vaginal birth with episiotomy or sutured perineal tear (aOR: 2.21, 95\% Cl: 1.5-3.2), operative vaginal birth (aOR: 2.60, 95\% Cl: 1.3-5.3) or caesarean section (aOR: $2.15,95 \% \mathrm{Cl}: 1.4-3.3$ ) compared to a vaginal birth with minimal or no perineal trauma. There was no association between timing of resumption of sex and the time interval between births. 
Conclusion For almost half of the cohort, sex was not resumed until at least eight weeks after the second birth. Timing of resumption of sex was influenced by obstetric factors, but not the time interval between births.

Keywords Method of birth, multiparous, perineal trauma, pregnancy cohort, resumption of sex

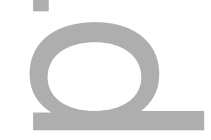

\section{Introduction}

Having a first baby is a major life transition impacting on women's physical and mental health and intimate partner relationships.(1) There is now a considerable body of research investigating the influence of pregnancy and childbirth on maternal postpartum physical and mental health, (2-10) but comparatively less research examining the impact of childbirth on women's sexual health. $(11,12)$ Studies that do report on women's postpartum sexual health, frequently lack the study power to assess factors influencing outcomes $(13,14)$, or have other limitations, such as a high attrition of study participants (15) or samples restricted to primiparae or women having a vaginal birth. $(16,17)$ As a result, the evidence to inform clinical practice and the information available for women regarding their sexual health after childbirth remains limited. $(11,18)$

Pregnancy and childbirth impact on women's postpartum sexual health and relationships in multifaceted ways, (19-22) via relationship transitions, (23) breastfeeding $(20,24,25)$ and paternal factors such as fathers' mental health and wellbeing.(26) There are conflicting findings in the literature regarding the contribution of method of birth and other obstetric factors to postpartum sexual health, largely because many studies are too small for meaningful_statistical comparisons, (27-29) and because of differing definitions and ways of measuring sexual difficulties and sexual function.(11)

This paper draws on longitudinal data collected in a prospective cohort study designed to investigate the natural history of common maternal health problems after first and subsequent births. We have reported on the resumption of sex after the first birth and associations with method of birth previously.(30) The objectives of the current paper are twofold, first, to investigate the timing of resumption of sex after a second birth; and 
second, to investigate whether timing of resumption of sex after a second birth is influenced by: (i) method of birth for the second birth, (ii) the combination of method of birth for the index (first) birth and second birth; or (iii) the interval between births.

\section{Methods}

\section{Sample and Participants}

A prospective pregnancy cohort of nulliparous women was recruited between 2003 and 2005 at six metropolitan public hospitals in Melbourne, Australia. To be eligible to take part women needed to be $\geq 18$ years, English speaking, and $\leq 24$ weeks' gestation. In the first phase of the study, women completed self-administered questionnaires and computerassisted telephone interviews in early and late pregnancy, and at 3, 6, 9, 12 and 18 months postpartum. Women who enrolled in the study and completed at least one follow-up questionnaire or telephone interview in the first phase of the study were eligible to take part in the second phase of follow-up, which involved follow-up four years after the index (first) birth, and six and 12 months after second and subsequent births. Follow-up after second and subsequent births ceased when the index child turned 10 years of age. The period of data collection after the second birth was from 2005 to 2015 . Further details regarding the study design, recruitment methods and procedures for follow-up are available in a published study protocol. (31)

All women in the cohort were mailed a formal invitation to take part in phase two of the study. This included a letter inviting them to take part in the next phase of the study, and a plain language statement explaining what would be involved. Women consenting to take part were encouraged to notify the research team (by phone, email or postcard) when they were expecting another baby, and when their baby was born. All participants received a study newsletter twice a year reminding them to let the research team know if they were expecting another baby. In addition, we contacted women every six to 12 months to update their contact details and remind them to let us know when they were pregnant and/or had had another baby. All correspondence from the research team included a copy of a reply paid postcard for women to use to notify the research team when they were pregnant or had recently had another baby.

The questionnaires mailed to women 6 and 12 months after second and subsequent births 
were similar in content to questionnaires completed after the index birth. Women were invited to complete the questionnaires and return them to the research team in a reply paid envelope. Women who did not return a completed questionnaire within two weeks were sent a reminder postcard, followed by a phone call two weeks later.

\section{Measures and definitions}

Questionnaires completed by mothers in the first and second phases of the study were B5 size booklets, approximately 40 pages in length, and included questions on a range of common maternal health problems, including sexual health issues. Previously validated instruments were used where possible. Questions on sexual health drew on the questions included in the Australian Longitudinal Women's Health Study (32) and a study by Barrett et al.(21) Information was collected that enabled us to categorise method of birth and degree of perineal trauma for the first and second births. Both women's self-report and hospital medical records were used to ascertain labor and birth events. A high level of congruity (98\%) was found between medical record data and women's own accounts of method of birth. $(33,34)$ Data from questionnaires have been used to categorise method of birth and perineal trauma as more complete data were available from study questionnaires for these variables. To ascertain method of birth, women were asked "How was your baby born?" Response categories included: vaginal birth, vaginal breech birth, birth assisted by forceps, vacuum extraction or ventouse, caesarean section after unsuccessful attempt to delivery your baby using forceps or vacuum extraction, caesarean section (no other procedures used first). To ascertain perineal trauma women were asked if they had an episiotomy (surgical cut to your perineum), whether they had a perineal tear, stitches for a tear or episiotomy or a tear that affected their rectum (with additional detail on anal sphincter and rectal lining involvement). Data on method of birth and degree of perineal trauma were combined to provide a single stratified measure for each birth allowing us to assess associations for different combinations, for example vaginal birth with/without perineal trauma. In order to investigate the extent to which the timing of resumption after the second child is influenced by the combination of method of birth for the index pregnancy and the current pregnancy, we created a summary variable that combined data on method of birth and degree of perineal trauma in both pregnancies.

Timing of resumption of intimate contact and resumption of vaginal sex was derived 
drawing on data collected at 3, 6, 9 and 12 months postpartum for the index (first) birth, and at 6 and 12 months postpartum for second births. Each questionnaire included two questions about timing of resumption of vaginal sex. Women who answered 'yes' to the question "Have you had vaginal intercourse since your baby was born?" were asked "When did you first have vaginal intercourse again (or attempted vaginal intercourse again) after you had your baby?" Priority was given to the first occasion on which women reported having had vaginal sex after their first and second births. Postnatal depressive symptoms were assessed using the Edinburgh Postnatal Depression Scale (EPDS), with a cut off score of $\geq 13$ used to identify women likely to be clinically depressed. (35) Exposure to intimate partner violence in the first 12 months postpartum after the second birth was assessed using the Composite Abuse Scale. $(36,37)$ Assessment of infant feeding included whether the infant had ever been breastfed, the type of feeds the baby was having at six months postpartum, and how old their baby was when they stopped breastfeeding (number of completed weeks). Babies having any breastfeeds were classified as breastfed for the purpose of the analysis. Tiredness was assessed at six months postpartum with the question "Since the birth have you ever experienced extreme tiredness or exhaustion?" with response options of 'never', 'rarely', 'occasionally' or 'often'. Women were classified as experiencing tiredness if they responded 'occasionally' or 'often'.

Data on social characteristics such as maternal age and country of birth were collected in the baseline questionnaire. Other social characteristics, such as maternal education and relationship status were assessed at each follow-up.

\section{Statistical Analysis}

Data were analysed using Stata version 14.(38) Factors associated with not having resumed vaginal sex within eight weeks of the second birth were investigated using univariable and multivariable logistic regression. The decision to examine factors associated with not having resumed sex within eight weeks of the second birth was an a priori decision based on the common assumption that everything will be 'back to normal' by around six weeks postpartum.(39, 40) Factors included at the univariable level included breastfeeding, extreme tiredness, relationship status, educational qualification, time interval between births, depressive symptoms and intimate partner violence. Multivariable analysis was used to examine (i) associations between method of birth and perineal trauma in the second 
birth and non-resumption of sex, and (ii) the extent to which the timing of resumption of sex after a second child is influenced by the method of birth and perineal trauma for the first and second births taking into account potential confounders. Maternal age was included in the multivariable models for a priori reasons based on evidence of associations between maternal age and sexual function found in other research.(41) Other variables were included in multivariable models based on observed associations in univariable analyses applying the following criteria: $95 \%$ confidence interval not crossing one and a significance level of $<0.01$. Data are presented as crude or adjusted odds ratios (ORs) with $95 \%$ confidence intervals $(95 \% \mathrm{Cl})$.

Ethics approval was granted by La Trobe University (2002/38), Royal Women's Hospital (2002/23), Southern Health (2002-099B), Angliss Hospital and The Royal Children's Hospital (27056A).

\section{Results}

\section{Participants}

A total of 1507 eligible women enrolled in the study. The mean gestation at enrolment was 15.0 weeks (range 6 to 24 weeks). At the time of giving birth to their first baby, participants ranged in age from 18.9 - 49.9 years (mean 31.0) The majority were Australian born (74.0\%), married $(60.7 \%)$ or living with a partner (34.6\%) and had post-secondary qualifications (72.1\%). Comparison of study participant characteristics with routinely collected Victorian Perinatal Data for nulliparous women giving birth as public patients during the period of recruitment showed that participants were representative in terms of method of birth and infant birthweight for the index birth, but younger women (18-24 years, 15.5\% versus $29.9 \%$ ) and women born overseas of non-English speaking background (16.2\% versus $21.0 \%)$ were under-represented.

Participation across waves of follow-up was excellent, with $90 \%$ of women completing follow-up 12 months after the index birth (See Figure 1). A total of 1345 women consented to follow-up after second and subsequent births, and three-quarters of these women had a second baby. Of these, 97 notified the research team of their baby's birth after six months 
postpartum. Prior to the six-month follow-up five women withdrew (two women were too busy, one woman had a stillbirth, two women did not specify a reason) and 10 were lost to follow-up. Of the remaining 898 women, $94.2 \%$ returned a completed six-month follow-up questionnaire. After the six-month follow-up two women withdrew (one woman due to illhealth, one woman was too busy). Fifty women notified the research team of the birth of their second child too late to be included in 12-month follow-up. A total of 943 women were sent the 12 -month questionnaire, $89.5 \%$ of whom returned a completed questionnaire to the research team.

Compared to women who returned the questionnaire six months after the birth of their second baby, women who did not respond were younger, had lower qualification levels, and were more likely to have a Health Care Card. Women who notified the team too late after the birth of their second child to be sent a six-month postpartum questionnaire did not differ significantly in age, education level or income from women who notified the team in time to be sent a six-month postpartum questionnaire. A significantly higher proportion of women who were born overseas in a non-English speaking country were not sent a sixmonth postpartum questionnaire due to late notification, than women who were born in Australia, or born overseas in an English speaking country $\left(X^{2}=11.9, p=0.003\right)$.

The mean number of years between the first and second birth was 2.7 years. The minimum

Two thirds of women (67.6\%) had a spontaneous vaginal birth for their second birth, with just over half of this group sustaining a sutured tear or episiotomy (53.1\%). Of the remaining women, $19.5 \%$ gave birth by caesarean prior to labor, $7.8 \%$ had an emergency caesarean during labor, and $5.1 \%(n=43)$ gave birth assisted by forceps $(n=20)$ or vacuum extraction $(n=23)$.

One in ten women resumed vaginal sex within four weeks of having their second baby, one in three within six weeks and just over half by eight weeks after the second birth (Table 1). 
Fewer women reported resuming vaginal sex in the first eight weeks after the second birth compared to the first birth. Whereas $65 \%$ of women resumed vaginal sex by eight weeks after their first birth, 56\% of women resumed sex by eight weeks after the second birth, with confidence intervals indicating that this difference is unlikely to have occurred by chance (Table 1).

Several factors were associated with timing of resumption of sex. Compared to women who had a vaginal birth with minimal or no perineal trauma, women who had a vaginal birth and a sutured tear or episiotomy, and those who had a caesarean section had raised odds of not resuming sex by eight weeks postpartum (Table 2 ). Older women ( $>=30$ years) were also more likely not to have resumed sex by eight weeks postpartum than younger women $(<30$ years). Other factors associated with non-resumption of sex by eight weeks after the second birth were: breastfeeding, and extreme tiredness in the first three months after childbirth. There were no differences in timing of resumption of sex after second births related to maternal education, relationship status, maternal depressive symptoms or exposure to intimate partner violence after the first birth. Nor was there any association between timing of resumption of sex after the second birth and the time interval between births. Method of birth remained significantly associated with timing of resumption of sex after adjusting for potential confounders. Even after adjusting for maternal age, breastfeeding and tiredness, the odds of non-resumption of sex by eight weeks postpartum were more than two times higher for women who had an operative vaginal birth, caesarean section or spontaneous vaginal birth accompanied by an episiotomy and/or sutured tear compared with women who had a vaginal birth with minimal or no perineal trauma (see Table 2).

Approximately $12 \%$ of women had a vaginal birth with minimal or no perineal trauma for the birth of both their first and second child. A higher proportion - one in three - had a vaginal birth with a sutured tear and/or episiotomy on both occasions. One in five women had a caesarean section for both births, $5 \%$ of women had a caesarean section for the first birth and vaginal birth for the second birth, and $5 \%$ had a vaginal birth for their first birth and caesarean section for the second (Table 3). One in five women had an operative vaginal birth for their first birth. A much smaller proportion of women had an operative vaginal birth for their second baby (around 5\%). In both cases, around half were assisted by forceps and half were assisted by vacuum extraction. 
Women who gave birth to their second child vaginally and sustained perineal trauma had five-fold higher odds of not resuming vaginal sex by eight weeks postpartum compared to women who had a vaginal birth for both their first and second births with minimal or no perineal trauma. Women who gave birth to both their first and second child by caesarean section had two-fold higher odds of not resuming sex by eight weeks, compared to women who had two vaginal births with minimal or no perineal trauma (Table 3). Similarly, women who had a vaginal birth with a sutured tear and/or an episiotomy for both births also had two-fold higher odds of not resuming sex by eight weeks postpartum, compared to women who had two vaginal births with minimal or no perineal trauma.

\section{Discussion}

In this prospective cohort of Australian mothers followed up for ten years after their first birth, around one in ten women that had a second birth in the study period had a spontaneous vaginal birth with an intact perineum for both births. More than one in five had a caesarean section for both births, and one in three had a vaginal birth with an episiotomy and/or sutured tear. Our findings demonstrate the extent to which obstetric intervention during childbirth has become normative for Australian women.

Just over half of women had resumed sex by eight weeks postpartum after their second birth. Women who had an operative vaginal birth, caesarean section or vaginal birth with an episiotomy or sutured tear resumed sex later than women who had a vaginal birth with an intact perineum. There was no evidence to suggest that having a caesarean section resulted in earlier resumption of vaginal sex, compared with vaginal birth. In fact, patterns of resumption of sex were strikingly similar for women who had an operative vaginal birth, spontaneous vaginal birth with an episiotomy or perineal tear and those having a caesarean section. Even after taking into account potential confounders, the odds of not having resumed sex by eight weeks postpartum were two times higher for women who any of these experiences compared to women who had a spontaneous vaginal birth with an intact perineum.

Whilst a number of studies of postnatal sexual health include multiparous women $(13,28$, 42-47), to our knowledge no other studies have undertaken prospective follow-up of a nulliparous cohort after first and subsequent births. The ability to follow up women after 
their first and subsequent births enabled consideration of the extent to which the time interval between births, and method of birth for the first and second birth, influence timing of resumption of sex. Our findings suggest that the time interval between first and second births has little bearing on timing of resumption of sex after the second of birth. On the other hand, the study provides evidence that method of birth in the first birth does have a bearing on timing of resumption of sex after the second birth. Women who had a caesarean section for their first birth had three-fold higher odds of resuming sex later than eight weeks postpartum even when they have a spontaneous vaginal birth with no perineal trauma in the second birth. It is possible that this reflects a legacy effect whereby timing of resumption of sex after the first birth influences couples' decisions about resumption of sex after a second birth. The group with the highest odds of not resuming vaginal sex by eight weeks postpartum were women who had vaginal birth with no perineal trauma for their first birth, and then had a vaginal birth with an episiotomy and/or sutured tear for their second birth. This may reflect a response to a more difficult second birth, although results must be interpreted with caution due to the wide confidence interval reflecting the small number of women experiencing this particular combination. Prior research has shown timing of resumption is associated with operative vaginal births, episiotomy and more severe perineal trauma. $(16,45,46,50)$ Other factors salient to timing of resumption of sex after a second birth are fatigue and breastfeeding, both of which are associated with later resumption of sex. These data lend support to prior findings. $(42,47,51)$ Previous longitudinal research found the impact of fatigue on a couple's sexual relationship an increasing problem over time (4 years compared to 6 months after an index birth) but unrelated to the number of subsequent children.(52) Counter-intuitively, neither depressive symptoms nor intimate partner violence appeared to have a marked effect on timing of resumption of sex after second births, although odds were raised in both cases. Similar findings have been reported in another large cross-sectional study. (47)

Adjusting to life with a new baby is a critical period in couple relationships. $(22,53)$ How well couples navigate this period has implications for long-term relationships and the health and well-being of the whole family. $(54,55)$ It is common for women and men to say that they didn't know what to expect after having a baby $(23,26)$, and research over the past four decades has called for more assistance for parents in the area of sexual health and postnatal 
relationship issues.(21, 26, 42, 56-60) Sex remains a taboo topic that can be difficult for women and men to bring up in consultations unless specifically asked whether they have any questions related to this issue. $(19,61)$ Clinicians may also be reluctant to raise the topic of sex, although qualitative studies show that women are generally appreciative of the opportunity to ask questions about sex after childbirth and to clarify any concerns.(62)

\section{Strengths and Limitations}

Strengths of the study include: (i) prospective data collection after first and second births; (ii) frequent follow-up and low attrition; (iii) excellent retention and participation in followup after second births; (iv) detailed measures assessing resumption of sex, method of birth and other obstetric covariates known to influence timing of resumption of sex. Study limitations include: the exclusion of women receiving maternity care in the private sector where rates of obstetric intervention are higher, and inability to consider differences between the experiences of women having different types of operative vaginal birth (i.e. forceps versus vacuum extraction and high versus low forceps). While data were collected on a range of obstetric events, the number of women experiencing each of these interventions was too small for meaningful statistical comparisons. Breastfeeding questions did not distinguish between exclusive, predominant or complementary breastfeeding. In addition, the length of the study questionnaires may have discouraged some women from participating and is a possible reason for the under-representation of younger women in the sample.

\section{Conclusion}

Our findings show that many couples do not resume sex after a second birth until at least the third month after childbirth. Both caesarean section and operative vaginal birth were associated with later resumption of sex after second births, compared to spontaneous vaginal birth with minimal perineal trauma. Time interval between births did not appear to influence timing of resumption of sex. Informing women and their partners that it is not unusual for couples to resume sex more than eight weeks after childbirth may be reassuring and reduce the pressure for everything to be 'back to normal' within six weeks of giving birth. 


\section{References}

331 1. Brown S, Lumley J, Small R, Astbury J. Missing Voices: the experience of motherhood.

332 Melbourne: Oxford University Press; 1994.

333 2. Woolhouse H, Perlen S, Gartland D, Brown SJ. Physical Health and Recovery in the First 18

334 Months Postpartum: Does Cesarean Section Reduce Long-Term Morbidity? Birth. 2012;39(3):221-9.

$3353 . \quad$ Schytt E, Lindmark G, Waldenstrom U. Physical symptoms after childbirth: prevalence and 336 associations with self-rated health. BJOG: An International Journal of Obstetrics and Gynaecology. $2005 ; 112(2): 210-7$.

338 4. Saurel-Cubizolles M-J, Romito P, Lelong N, Ancel P-Y. Women's health after childbirth: a longitudinal study in France and Italy. BJOG: An International Journal of Obstetrics and Gynaecology. 2000;107(10):1202-9.

3415 5. Lydon-Rochelle MT, Holt VL, Martin DP. Delivery method and self-reported postpartum general health status among primiparous women. Paediatric and Perinatal Epidemiology. 2001;15(3):232-40.

6. Glazener C, Abdall M, Stroud P, Naji S, Templeton A, Russell I. Postnatal maternal morbidity: extent, causes, prevention and treatment. BJOG: An International Journal of Obstetrics and Gynaecology. 1995;102:282-7.

347 7. Brown S, Lumley J. Maternal health after childbirth: results of an Australian population

348 based survey. BJOG: An International Journal of Obstetrics and Gynaecology. 1998;105(2):156-61.

349 8. Cruise SM, Layte R, Stevenson M, O'Reilly D. Prevalence and factors associated with 350 depression and depression-related healthcare access in mothers of 9-month-old infants in the 351 Republic of Ireland. Epidemiology and Psychiatric Sciences. 2017:1-11.

352 9. Gavin NL, Gaynes BN, Lohr KN. Perinatal depression: a systematic review of prevalence and 353 incidence. Obstetrics and Gynecology. 2005;106:1071-83.

354 10. Heron J, O'Connor TG, Evans J, Golding J, Glover V, the Alspac Study Team. The course of 355 anxiety and depression through pregnancy and the postpartum in a community sample. Journal of 356 Affective Disorders. 2004;80(1):65-73.

357 11. Leeman LM, Rogers RG. Sex after childbirth: postpartum sexual function. Obstetrics \& 358 Gynecology. 2012;119(3):647-55.

359 12. Jawed-Wessel S, Sevick E. The Impact of Pregnancy and Childbirth on Sexual Behaviors: A 360 Systematic Review. The Journal of Sex Research. 2017. 
13. Faisal-Cury A, Menezes PR, Quayle J, Matijasevich A, Diniz SG. The Relationship Between Mode of Delivery and Sexual Health Outcomes after Childbirth. Journal of Sexual Medicine. 2015(5):1212.

14. Lurie S, Aizenberg M, Sulema V, Boaz M, Kovo M, Golan A, et al. Sexual function after childbirth by mode of delivery: a prospective study. Arch Gynecol Obstet. 2013;288(4):785-92. 15. De Souza A, Dwyer PL, Charity M, Thomas E, Ferreira CHJ, Schierlitz L. The effects of mode delivery on postpartum sexual function: a prospective study. BJOG. 2015;122:1410-8. 16. Buhling KJ, Schmidt S, Robinson JN, Klapp C, Siebert G, Dudenhausen JW. Rate of dyspareunia after delivery in primiparae according to mode of delivery. European Journal of Obstetrics, Gynecology, and Reproductive Biology. 2006;124(1):42-6.

17. Ejegard $H$, Ryding EL, Sjogren B. Sexuality after delivery with episiotomy: a long-term followup. Gynecologic and obstetric investigation. 2008;66(1):1-7.

18. Abdool Z, Thakar R, Sultan AH. Postpartum female sexual function. European journal of obstetrics, gynecology, and reproductive biology. 2009;145(2):133-7. 19. Olsson A, Lundqvist M, Faxelid E, Nissen E. Women's thoughts about sexual life after childbirth: focus group discussions with women after childbirth. Scandinavian Journal of Caring Sciences. 2005;19(4):381-7.

20. Morof D, Barrett G, Peacock J, Victor CR, Manyonda I. Postnatal depression and sexual health after childbirth. Obstetrics and Gynecology. 2003;102(6):1318-25.

21. Barrett G, Pendry E, Peacock J, Victor C, Thakar R, Manyonda I. Women's sexual health after childbirth. BJOG: An International Journal of Obstetrics and Gynaecology. 2000;107(2):186-95. 22. Kristine L, Jane G. Making Love After Birth. Birth. 1980;7(3):181-5.

23. Woolhouse $H$, McDonald E, Brown S. Women's experiences of sex and intimacy after childbirth: making the adjustment to motherhood. Journal of Psychosomatic Obstetrics \& Gynecology. 2012;33(4):185-90.

24. Barbara G, Pifarotti P, Facchin F, Cortinovis I, Dridi D, Ronchetti C, et al. Impact of mode of delivery on female postpartum sexual functioning: spontaneous vaginal delivery and operative vaginal delivery vs cesearean section. Journal of Sexual Medicine. 2016;13(3):393-401.

25. Visness CM, Kennedy KI. The frequency of coitus during breastfeeding. Birth (Berkeley, Calif). $1997 ; 24(4): 253-7$.

26. Olsson A, Robertson E, Bjorklund A, Nissen E. Fatherhood in focus, sexual activity can wait: new fathers' experience about sexual life after childbirth. Scandinavian Journal of Caring Sciences. 2010;24(4):716-25.

This article is protected by copyright. All rights reserved 
27. Andrews V, Thakar R, Sultan AH, Jones PW. Evaluation of postpartum perineal pain and dyspareunia-A prospective study. European Journal of Obstetrics \& Gynecology and Reproductive Biology. 2008;137(2):152-6.

28. Elliott SA, Watson JP. Sex during pregnancy and the first postnatal year. Journal of Psychosomatic Research. 1985;29(5):541-8.

29. Odar E, Wandabwa J, Kiondo P. Sexual practices of women within six months of childbirth in Mulago hospital, Uganda. African Health Sciences. 2003;3(3):117-23.

30. McDonald E, Brown S. Does method of birth make a difference to when women resume sex after childbirth? BJOG: An International Journal of Obstetrics and Gynaecology. 2013;120(7):823-30. 31. Brown S, Lumley J, McDonald E, et al. Maternal Health Study: a prospective cohort study of nulliparous women recruited in early pregnancy. BMC Pregnancy Childbirth. 2006;6(12).

32. Brown WJ, Bryson L, Byles JE, Dobson AJ, Lee C, Mishra G, et al. Women's Health Australia: Recruitment for a National Longitudinal Cohort Study. Women \& Health. 1999;28(1):23-40. 33. Gartland D, Lansakara N, Flood M, Brown SJ. Assessing obstetric risk factors for maternal morbidity: congruity between medical records and mothers' reports of obstetric exposures. Am J Obstet Gynecol. 2012;206(2):152 e1- e10.

34. Brown SJ, Gartland D, Donath S, MacArthur C. Fecal incontinence during the first 12 months postpartum: complex causal pathways and implications for clinical practice. Obstet Gynecol. 2012;119(2 Pt 1):240-9.

35. Cox J.Perinatal mental health: a guide to the Edinburgh Postnatal Depression Scale (EPDS). London: Gaskell; 2003.

36. Hegarty K, Bush R, Sheehan M. The composite abuse scale: Further development and assessment of reliability and validity of a multidimensional partner abuse measure in clinical settings. Violence Victims. 2005;20(5):529-47.

37. Hegarty KL, Sheehan M, Schonfeld C. A multidimensional definition of partner abuse: Development and preliminary validation of the Composite Abuse Scale. Journal of Family Violence. 1999;14(4):399-414.

38. StataCorp. Stata Statistical Software: Release 14. College Station, TX: StataCorp LP; 2015. 39. Beischer NA, Mackay EV, Colditz PB. Obstetrics and the Newborn: An Illustrated Textbook. 3rd ed. London: Saunders; 1997.

40. Fraser DM, Cooper MA. Myles textbook for midwives. Edinburgh: Churchill Livingstone; 2009.

41. Richters J, Grulich AE, De Visser RO, Smith AMA, Rissel C. Sex in Australia: sexual and emotional satisfaction in regular relationships and preferred frequency of sex among a 
representative sample of adults. [The Australian Study of Health and Relationships, a survey of 19,307 people aged 16-59 years which had a broad focus across many aspects of sexual and reproductive health.]. Australian and New Zealand Journal of Public Health. 2003;27(2):171-9. 42. Glazener CMA. Sexual function after childbirth: women's experiences, persistent morbidity and lack of professional recognition. BJOG: An International Journal of Obstetrics and Gynaecology. 1997;104(3):330-5.

43. Hyde JS, DeLamater JD, Plant EA, Byrd JM. Sexuality during pregnancy and the year postpartum. The Journal of Sex Research. 1996;33(2):143.

44. Khajehei M, Doherty M, Tilley PJM, Sauer K. Prevalence and Risk Factors of Sexual Dysfunction in Postpartum Australian Women. Journal of Sexual Medicine. 2015(6):1415. 45. Grudzinskas JG, Atkinson L. Sexual function during the puerperium. Archives of Sexual Behavior. 1984;13(1):85-91.

46. Klein MC, Gauthier RJ, Robbins JM, Kaczorowski J, Jorgensen SH, Franco ED, et al.

441 Relationship of Episiotomy to Perineal Trauma and Morbidity, Sexual Dysfunction, and Pelvic Floor 442 Relaxation. American Journal of Obstetrics \& Gynecology. 1994;171(3):591-8.

443 47. Radestad I, Olsson A, Nissen E, Rubertsson C. Tears in the vagina, perineum, sphincter ani, 444 and rectum and first sexual intercourse after childbirth: A nationwide follow-up. Birth. 2008;35(2):98-106.

48. Ford JB, Bentley JP, Morris JM, Roberts CL. Factors associated with changes into public or private maternity care for a second pregnancy. Australian Health Review. 2013(4):495. 49. Chen JS, Ford JB, Ampt A, Simpson JM, Roberts CL. Characteristics in the First Vaginal Birth and Their Association with Mode of Delivery in the Subsequent Birth. Paediatric \& Perinatal Epidemiology. 2013;27(2):109-17. 50. Signorello LB, Harlow BL, Chekos AK, Repke JT. Postpartum sexual functioning and its relationship to perineal trauma: A retrospective cohort study of primiparous women. American Journal of Obstetrics and Gynecology. 2001;184(5):881-90. 51. Barbara G, Pifarotti P, Ronchetti C, Calzolari L, Facchin F, Cortinovis I, et al. Impact of Mode of Delivery on Female Postpartum Sexual Functioning: Spontaneous Vaginal Delivery and Operative Vaginal Delivery vs Cesarean Section. The Journal of Sexual Medicine. 2016;13:393-401.

457 52. Ahlborg T, Misvaer N, Möller A. Perception of marital quality by parents with small children: 458 a follow-up study when the firstborn is 4 years old. Journal of Family Nursing. 2009;15(2):237-63.

459 53. Delicate A, Ayers S, McMullen S. Review Article: A systematic review and meta-synthesis of 460 the impact of becoming parents on the couple relationship. Midwifery. 2018;61:88-96. 
54. Foux R. Sex education in pregnancy: does it exist? A literature review. Sexual \& Relationship Therapy. 2008;23(3):271-7. 55. Gungor S, Baser I, Ceyhan S, Karasahin E, Acikel CH. Mode of delivery and subsequent longterm sexual function of primiparous women. Int J Impot Res. 2007;19(4):358-65. 56. von Sydow K. Sexuality during pregnancy and after childbirth: A metacontent analysis of 59 studies. Journal of Psychosomatic Research. 1999;47(1):27-49. 57. Ahlborg T, Dahlof L, Hallberg LRM. Quality of the intimate and sexual relationship in firsttime parents six months after delivery. 2005;42(2):167(8).

58. Woolhouse $H$, McDonald E, Brown S. Changes to sexual and intimate relationships in the postnatal period: women's experiences with health professionals. Australian Journal of Primary Health. 2014;20(3):298-304. 59. Nancy D. Sexuality in Pregnancy And the Puerperium. Birth. 1974;1(4):5-9. 60. Lumley J. Sexual feelings in pregnancy and after childbirth. Australian and New Zealand Journal of Obstetrics and Gynaecology. 1978;18:114-7. 61. McDonald EA, Woolhouse $\mathrm{H}$, Brown $\mathrm{S}$. Consultation about sexual health issues in the year after childbirth: a cohort study. Birth. 2015.

62. Brandenburg $\mathrm{U}$, Bitzer J. The challenge of talking about sex: The importance of patientphysician interaction. Maturitas. 2009;63(2):124-7.

Table 1. Resumption of vaginal sex after first births (from 2003 to 2006) and second births (from 2005 to 2015) in Melbourne, Australia

\begin{tabular}{|c|c|c|c|c|c|c|}
\hline 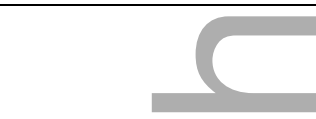 & \multicolumn{3}{|c|}{$\begin{array}{l}\text { After the first birth } \\
\qquad(n=1425)\end{array}$} & \multicolumn{3}{|c|}{$\begin{array}{l}\text { After the second birth } \\
\qquad(\mathrm{n}=895)\end{array}$} \\
\hline 5 & $n(\%)$ & Cum. \% & $95 \% \mathrm{Cl}$ & n (\%) & Cum. \% & $95 \% \mathrm{Cl}$ \\
\hline $1^{\text {st }} 4$ weeks & $216(15.2)$ & 15.2 & $13.3-17.1$ & 98 (11.0) & 11.0 & $9.0-13.2$ \\
\hline 5-6 weeks & $368(25.8)$ & 41.0 & $38.4-43.6$ & 205 (22.9) & 33.9 & $30.8-37.1$ \\
\hline 7-8 weeks & 341 (23.9) & 64.9 & $62.4-67.4$ & $198(22.1)$ & 56.0 & $52.7-59.3$ \\
\hline 9-12 weeks & 195 (13.7) & 78.6 & $76.4-80.7$ & 179 (20.0) & 76.0 & $73.0-78.7$ \\
\hline 3-4 months & $186(13.1)$ & 91.7 & $90.1-93.0$ & 98 (11.0) & 87.0 & $84.5-89.1$ \\
\hline 5-6 months & $50(3.5)$ & 95.2 & $93.9-96.2$ & $50(5.6)$ & 92.5 & $90.6-94.2$ \\
\hline
\end{tabular}




\begin{tabular}{|l|r|r|r|r|r|r|}
\hline 7-9 months & $28(2.0)$ & 97.1 & $96.1-97.9$ & $27(3.0)$ & 95.5 & $94.0-96.8$ \\
\hline $\mathbf{1 0 - 1 2}$ months & $11(0.8)$ & 97.9 & $97.0-98.6$ & $7(0.8)$ & 96.3 & $94.9-97.5$ \\
\hline $\begin{array}{l}\text { Not resumed by 12 } \\
\text { months }\end{array}$ & $30(2.1)$ & 100.0 & $99.7-100$ & $33(3.7)$ & 100.0 & $99.6-100$ \\
\hline
\end{tabular}

485

486 Table 2. Relationship between method of birth, perineal trauma and non-resumption of vaginal

487 sex by eight weeks after second birth from 2005 to 2015*

488

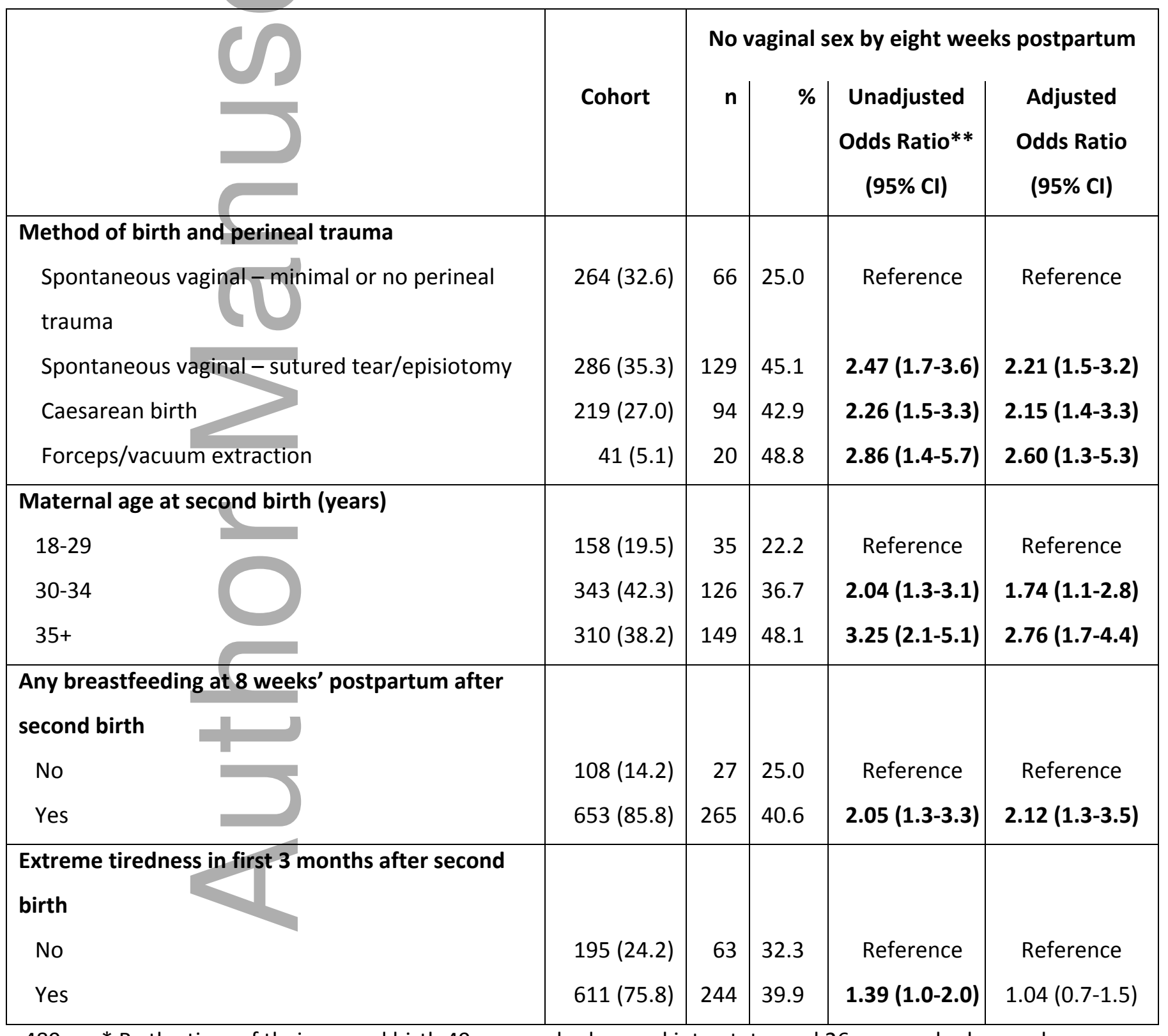

$489 *$ By the time of their second birth 49 women had moved interstate, and 26 women had moved

490 overseas. The remainder of the cohort gave birth in Victoria, Australia 
** Data relating to the associations between resumption of vaginal sex at eight weeks postpartum

492 and relationship status, highest educational qualification level, time interval between births,

493 depressive symptoms, as measured by the Edinburgh Postnatal Depression Scale (EPDS) and

494 intimate partner violence, as measured by the Composite Abuse Scale (CAS), were not included due 495 to lack of significance at the univariable level.

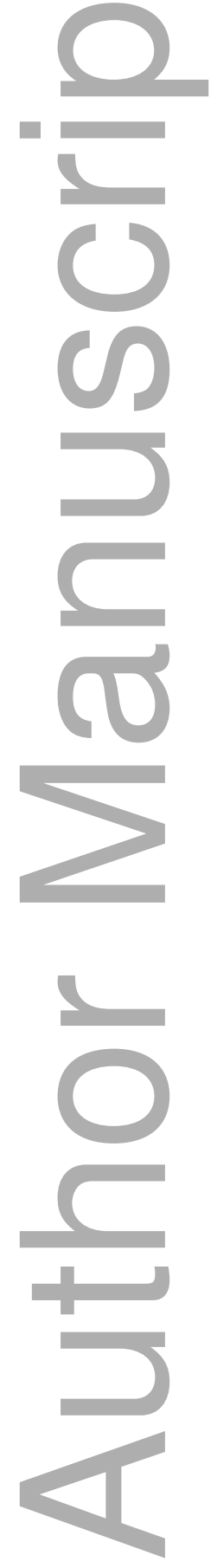


Table 3. Relationship between method of birth for first and second birth and non-resumption of vaginal sex by eight weeks after second birth from 2005 to 2015 *

\begin{tabular}{|c|c|c|c|c|}
\hline \multirow{2}{*}{ Index birth** } & \multirow{2}{*}{ Second birth } & \multirow{2}{*}{$\begin{array}{c}\text { TOTAL }^{*} \\
\mathbf{N}(\%)\end{array}$} & \multicolumn{2}{|c|}{$\begin{array}{c}\text { No vaginal sex by eight weeks } \\
\text { postpartum }\end{array}$} \\
\hline & & & n (\%) & $\begin{array}{r}\text { Adjusted Odds } \\
\text { Ratio*** }(95 \% \mathrm{Cl})\end{array}$ \\
\hline Vaginal birth with minimal or no perineal trauma & Vaginal birth with minimal or no perineal trauma & $98(12.3)$ & $25(25.5)$ & Reference \\
\hline Vaginal birth with minimal or no perineal trauma & Vaginal birth with sutured tear or episiotomy & $19(2.4)$ & $12(63.2)$ & $5.05(1.7-15.3)$ \\
\hline Vaginal birth with sutured tear or episiotomy & Vaginal birth with minimal or no perineal trauma & $156(19.7)$ & $37(23.7)$ & $1.06(0.6-2.0)$ \\
\hline Vaginal birth with sutured tear or episiotomy & Vaginal birth with sutured tear or episiotomy & $262(33.0)$ & 115 (43.9) & $2.26(1.3-3.9)$ \\
\hline Vaginal birth - any & Caesarean Section & $39(4.9)$ & $17(43.6)$ & $1.98(0.8-4.7)$ \\
\hline Caesarean Section & Vaginal birth - any & $45(5.7)$ & $23(51.1)$ & $3.15(1.4-6.9)$ \\
\hline Caesarean Section & Caesarean Section & $175(22.0)$ & $75(42.9)$ & $2.40(1.3-4.4)$ \\
\hline r & & $794(100.0)$ & $304(38.3)$ & \\
\hline
\end{tabular}

* By the time of their second birth 49 women had moved interstate, and 26 women had moved overseas. The remainder of the cohort gave birth in Victoria, Australia 
** Other combinations were not considered due to small n's. These include first and second vaginal births assisted by forceps or vacuum extraction. These data were collapsed into vaginal birth with sutured tear or episiotomy. In addition vaginal first births followed by a caesarean section were collapsed into one group due to low numbers.

*** Adjusted for time interval between $1^{\text {st }}$ and $2^{\text {nd }}$ births, maternal age, tiredness ( 3 months postpartum) and breastfeeding ( 8 weeks postpartum) $¥$ Method of second birth detail was available for 845 women. For this group of women method of first birth detail was available for 829 women. 16 had missing data. Of the 829 women for whom first and second birth detail was available 35 women had missing data for the timing of resumption of vaginal sex.

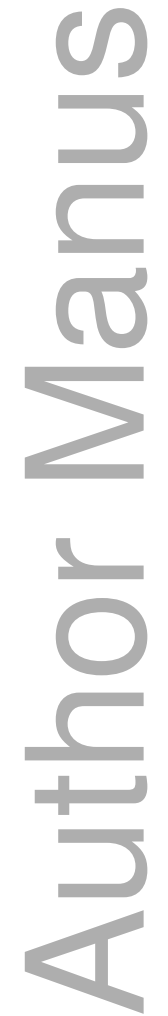

This article is protected by copyright. All rights reserved 


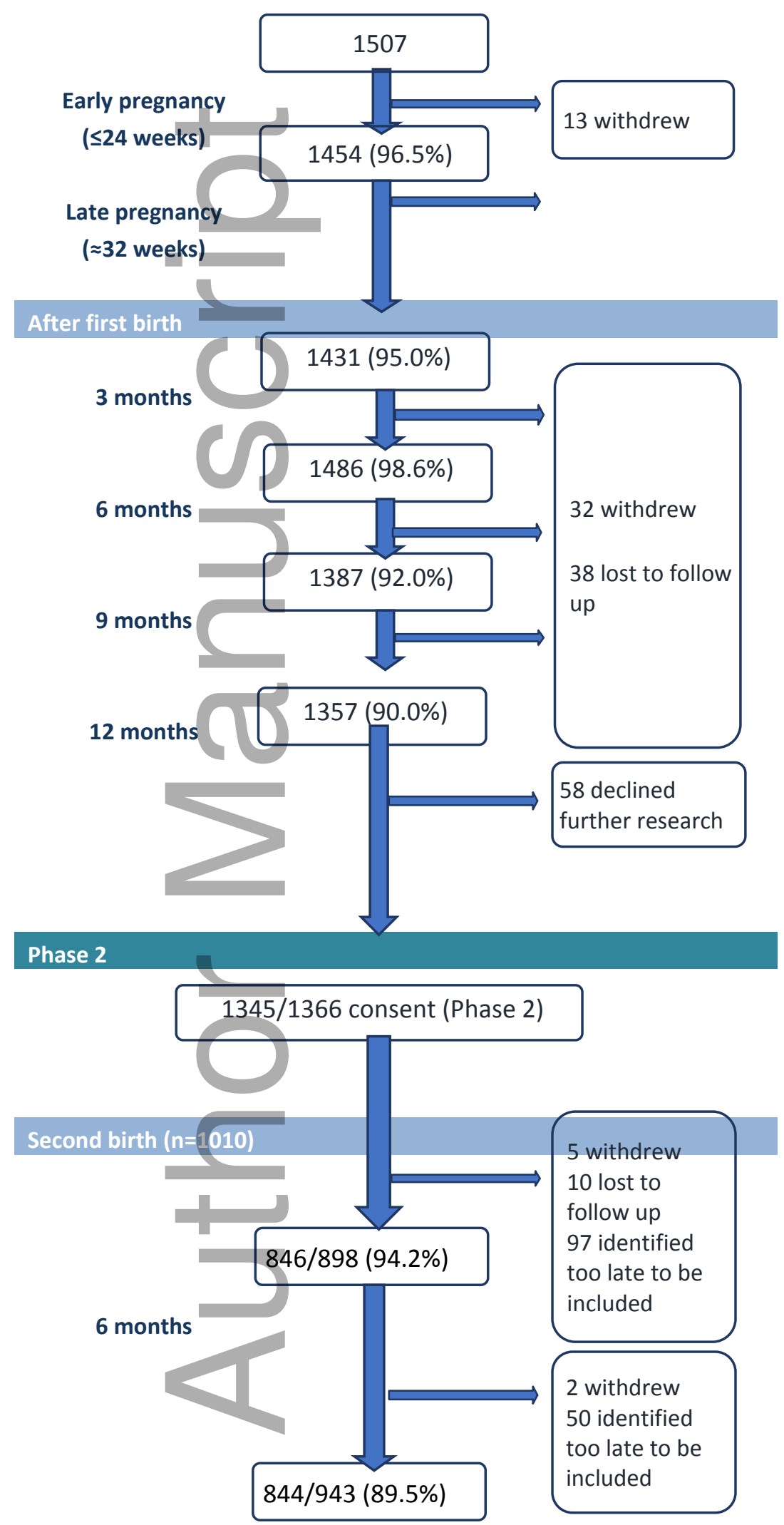

12 months

\section{Figure 1. Flowchart of participation}

This article is protected by copyright. All rights reserved 


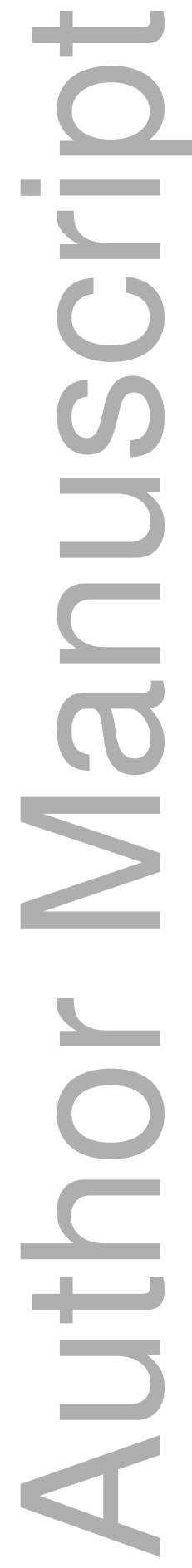

This article is protected by copyright. All rights reserved 


\section{University Library}

\section{- M M I N E R VA A gateway to Melbourne's research publications}

Minerva Access is the Institutional Repository of The University of Melbourne

Author/s:

McDonald, EA;Gartland, D;Woolhouse, H;Brown, SJ

Title:

Resumption of sex after a second birth: An Australian prospective cohort

Date:

2019-03-01

Citation:

McDonald, E. A., Gartland, D., Woolhouse, H. \& Brown, S. J. (2019). Resumption of sex after a second birth: An Australian prospective cohort. BIRTH-ISSUES IN PERINATAL CARE, 46 (1), pp.173-181. https://doi.org/10.1111/birt.12363.

Persistent Link:

http://hdl.handle.net/11343/284234 